\title{
Statistical behaviour of the deformation for first loading of polycrystalline ice
}

\author{
LORNE W. GOLD \\ Institute for Marine Dynamics, National Research Council of Canada, P.O. Box 12093, St. Fohn's, Nerefoundland A1B 3T5, Canada \\ E-mail: lorne.gold@nrc.ca
}

\begin{abstract}
A statistical analysis of the lengths of grain-boundary and transgranular cracks induced during the initial straining of columnar-grain ice by a compressive load applied perpendicular to the long direction of the columns is presented. The analysis shows that the crack lengths are randomly distributed and form distinct but correlated populations. The lognormal distribution function is shown to be a good descriptor of the populations for $5-90 \%$ of their range. Statistical models are presented for the lognormal behaviour of the crack-length distribution and for the strain dependence of the crack density. The models assume that a change in the value of the random variable of the respective population depends on the population value of the variable at the time of the change. It is shown that the model for the strain dependence of the crack density is suitable for the strain dependence of the acoustic emission, measured in both columnar-grain and granular ice subject to constant compressive loads. Evidence is also presented for a lognormal dependence of the dislocation density on strain. The analysis demonstrates that the cracks that form during the initial straining of polycrystalline ice are independent, random events and that the resulting crack populations are precursors to failure by fracture.
\end{abstract}

\section{INTRODUGTION}

Yield and failure of polycrystalline ice have been important research topics for several years. Much of this interest in the past 30 years has been driven by practical problems such as the determination of the forces that ice can apply to shoreline and offshore structures and of the loads that can be placed safely on ice covers.

Many measurements have been made of the strength of ice and of ice covers and of the dependence of the strength on variables such as ice type, strain rate, temperature and grain-size (Sanderson, 1988). Models for the strength have been developed based principally on two approaches: extension of pre-existing cracks (Schulson, 1996) and collapse caused by strain-dependent damage due to the formation of cracks of the order of grain-size in length (Sinha, 1991; Xiao and Jordaan, 1996). These models have been shown to be generally consistent with the deformation behaviour and values of strength measured in the laboratory and under larger-scale conditions when reasonable values are used for the properties of the ice.

The macro-scale processes of yield and failure have their beginning in inter- and intra-crystalline, microscale processes. These processes depend on the structure of the ice and determine the initial response to imposed boundary conditions. Dislocation processes, in particular, play a dominant role in the time-dependent response of ice to loads (Weertman, 1973). The inability of grains in polycrystalline ice to conform easily to the change in shape of neighbouring grains is important, also, as it causes stress concentrations that can initiate cracks and other modes of deformation (Frost and Gupta , 1993). Petrenko and Whitworth (1999) give a brief overview of some macro-scale manifestations of microscale processes.

At the microscale level, the structure of polycrystalline ice is quite variable due, for example, to variations in grain-size, grain shape and crystallographic orientation. It would be expected, therefore, that equations relating microscale deformation processes to macro-scale yield and strength measurements would be statistical in nature ( $\mathrm{Wu}$ and $\mathrm{Niu}$, 1995; Kim and Shyam Sunder, 1997). The development of these statistical equations requires assumptions concerning the spatial distribution of stress singularities and calculation of the time-dependent stresses and strains they induce. Such equations can give only the expected value, variance and other statistical properties of a particular macro-scale property. Conversely, for the same statistical reasons, macro-scale measurements can give only the expected value and other statistical properties of a relevant microscale population.

An example of the foregoing is the prediction of the tensile strength of ice using a dislocation model for crack initiation. Such models show that a stress equal to the tensile strength can produce a crack of a size that would propagate according to the Griffith theory of failure (Gold, 1977). Knowing only the mean and standard deviation for the tensile strength, however, although giving some indication of the statistical nature of the causative events, provides no incontrovertible evidence of what those events might be. A second example is the calculation of the elastic moduli of multigrain ice from the elastic moduli of the single crystal grains. This calculation, based on assumptions concerning the crystallographic orientations of the grains and interactions between them, gives values for the moduli that are consistent with measurements (Sinha, 1989). 
Table 1. The mean $\ln \left(\right.$ crack length), $\overline{\ln (\mathrm{cl})}$; variance, $s^{2}$; skewness, $\gamma_{1}$; and excess, $\gamma_{2}$, for the grain-boundary crack-length distributions for specimens of average grain-size, $d$, and number of cracks, $n$, subject to a constant strain rate; $T=-10^{\circ} \mathrm{C}$

\begin{tabular}{|c|c|c|c|c|c|c|c|c|c|c|c|c|c|c|c|c|c|}
\hline \multicolumn{6}{|c|}{ Strain rate $7.6 \times 10^{-4} \mathrm{~s}^{-1}$} & \multicolumn{6}{|c|}{ Strain rate $7.6 \times 10^{-5} s^{-1}$} & \multicolumn{6}{|c|}{ Strain rate $7.8 \times 10^{-6} \mathrm{~s}^{-1}$} \\
\hline$d$ & $n$ & $\overline{\ln (\mathrm{cl})}$ & $s^{2}$ & $\gamma_{1}$ & $\gamma_{2}$ & $d$ & $n$ & $\overline{\ln (\mathrm{cl})}$ & $s^{2}$ & $\gamma_{1}$ & $\gamma_{2}$ & $d$ & $n$ & $\overline{\ln (\mathrm{cl})}$ & $s^{2}$ & $\gamma_{1}$ & $\gamma_{2}$ \\
\hline $\mathrm{mm}$ & & & & & & $\mathrm{mm}$ & & & & & & $\mathrm{mm}$ & & & & & \\
\hline 2.4 & 28 & -0.53 & 0.35 & -0.55 & -0.44 & 2.4 & 39 & -0.38 & 0.25 & -0.41 & 1.14 & 2.5 & 21 & -0.21 & 0.69 & -0.25 & -1.40 \\
\hline 2.4 & 38 & -0.46 & 0.43 & -0.79 & 0.25 & 2.5 & 19 & -0.70 & 0.21 & -0.37 & -0.56 & 2.8 & 22 & 0.07 & 0.49 & -0.14 & -1.30 \\
\hline 2.8 & 35 & -0.38 & 0.40 & 0.08 & -1.14 & 2.6 & 28 & -0.48 & 0.36 & -0.50 & 0.11 & 2.8 & 39 & 0.10 & 0.26 & -0.12 & 0.15 \\
\hline 3.3 & 39 & -0.21 & 0.37 & -0.20 & 0.30 & 2.6 & 38 & -0.01 & 0.43 & -0.56 & -0.38 & 3.5 & 36 & 0.20 & 0.42 & -0.22 & -0.16 \\
\hline 3.4 & 33 & -0.33 & 0.58 & -0.26 & -0.67 & 2.6 & 44 & -0.23 & 0.41 & -0.09 & -0.71 & 3.9 & 26 & -0.10 & 0.55 & -0.08 & -0.24 \\
\hline 3.6 & 28 & -0.28 & 0.37 & 0.05 & -1.06 & 3.9 & 32 & 0.00 & 0.43 & -0.08 & -0.43 & 4.5 & 36 & -0.04 & 0.73 & 0.11 & -0.98 \\
\hline 3.9 & 33 & -0.29 & 0.51 & 0.11 & -1.20 & 3.9 & 22 & -0.19 & 0.39 & 0.24 & -0.92 & 4.7 & 23 & 0.32 & 0.42 & -0.14 & -0.89 \\
\hline 4.3 & 41 & -0.50 & 0.45 & -0.21 & -0.58 & 4.6 & 19 & 0.12 & 0.82 & 0.12 & -1.18 & 4.7 & 27 & 0.12 & 0.62 & 0.19 & -1.25 \\
\hline 4.6 & 37 & -0.41 & 0.35 & 0.18 & -0.82 & 6.2 & 13 & 0.38 & 0.82 & -0.98 & -0.09 & 5.2 & 16 & 0.41 & 0.24 & -0.57 & -0.71 \\
\hline 5.1 & 29 & -0.42 & 0.41 & 0.14 & 0.29 & 6.3 & 25 & 0.01 & 1.29 & 0.95 & -0.25 & 5.2 & 11 & 0.79 & 0.84 & 0.00 & -1.67 \\
\hline 5.2 & 34 & -0.42 & 0.50 & -0.09 & -1.42 & 6.4 & 34 & -0.01 & 0.99 & -0.32 & -0.84 & 5.5 & 23 & 0.33 & 0.54 & -0.67 & 0.03 \\
\hline 5.7 & 32 & -0.07 & 0.53 & 0.24 & -0.23 & 6.7 & 26 & 0.07 & 0.44 & -0.53 & -0.77 & 5.7 & 23 & 0.38 & 0.60 & 0.15 & -0.91 \\
\hline 5.9 & 12 & -0.34 & 0.58 & -0.42 & -1.20 & 7.9 & 17 & 0.15 & 0.45 & 0.30 & -0.71 & 7.5 & 21 & 0.50 & 0.53 & 0.27 & -0.48 \\
\hline 6.2 & 25 & -0.01 & 0.51 & -0.24 & -0.56 & 8.5 & 21 & 0.69 & 0.56 & -0.09 & -1.11 & 7.7 & 21 & 1.20 & 0.70 & -0.78 & -0.02 \\
\hline 7.0 & 31 & -0.01 & 0.63 & -0.10 & 0.17 & & & & & & & & & & & & \\
\hline 7.1 & 12 & -0.23 & 0.46 & -0.34 & -0.58 & & & ain rate & $7 \times 10$ & $s^{-1}$ & & & & & & & \\
\hline 7.7 & 22 & -0.66 & 0.60 & 0.55 & 1.28 & 2.8 & 75 & -0.54 & 0.40 & -0.03 & -0.46 & & & & & & \\
\hline 8.6 & 42 & -0.40 & 0.74 & -0.50 & -0.28 & 3.6 & 55 & -0.45 & 0.41 & -0.20 & -0.53 & & & & & & \\
\hline 9.2 & 26 & -0.25 & 0.60 & 1.58 & 2.11 & & & & & & & & & & & & \\
\hline
\end{tabular}

Gold (1972a, b, 1997, 1999b) found that the development of crack populations during the initial compressive straining of columnar-grain ice appeared to be a statistically definable random process. If this is the case, then the mean, standard deviation and other statistical characteristics of the populations should provide useful information on the corresponding characteristics of the microscale processes causing the cracks. The purpose of this paper is to provide additional evidence that the populations observed consist of independent, random events and can be described by suitable probability functions.

This is a particularly interesting response of a material to initial strain, and ice is very suitable for a study of this behaviour. It is transparent and normally exists at a temperature near to that at which it melts. Its thermal expansion can be considered isotropic (Petrenko and Whitworth, 1999), so internal stresses due to cooling should have relatively little effect on the initial dislocation density. In addition, ice single crystals have only one degree of freedom for easy deformation, and it is in the basal plane perpendicular to the axis of hexagonal symmetry (Glen and Perutz, 1954). This greatly constrains polycrystalline ice from conforming to a constant volume change in shape, causing stress singularities and a variable internal stress (Gold, 1963).

The ice used in the experiments referenced above was columnar-grain, with the axis of hexagonal crystallographic symmetry of the grains randomly oriented. For this type of ice and a load applied perpendicular to the long direction of the grains, the strain-induced cracks are long and narrow, with their long direction in the long direction of the grains. The initial strain for this combination of ice structure, direction of application of load, and limited degrees of freedom for deformation was found to be essentially two-dimensional.

The cracks were easily seen by the reflection of light from a source on each side of the specimens. Their rate of formation was sufficiently low in the constant-load tests that they could be counted as they formed. Avideo camera was used to record their formation in the constant-strain-rate tests. The video record was synchronized to the record of the time dependence of the strain, which allowed the time of formation of each crack to be determined to one-thirtieth of a second. The cracks formed abruptly and did not appear to increase in size for strain up to about $60 \%$ of that for brittle failure and for strain greater than that for ductile behaviour. This suggests that a crack effectively removes a singularity and most of the associated strain energy in its formation.

The specimens were sectioned at their mid-plane immediately after each test, and the length of the cracks perpendicular to their long direction was measured. To the extent that crack length is a measure of that strain energy for twodimensional strain, the statistical distribution in the crack lengths should be reasonably representative of the internal strain-energy distribution. It would be expected, therefore, that the statistical characteristics of compressive-strain induced crack populations should reflect those of the internal strain-energy distribution associated with stress singularities.

It was found in the above studies that the lognormal distribution function provided a good description of the distribution in crack lengths at a given strain, and of the strain dependence of the crack density. In section 2 of this paper, information is presented on the limitations of this function for describing the crack-length populations, as shown by the skewness and excess calculated for the crack population induced in each test specimen. It is shown also that the grain-boundary and transgranular cracks form separate but correlated populations. Statistically based models for the lognormal dependence of the crack-length distribution and for the lognormal dependence of the crack density on strain, are presented in section 3. This is followed by evidence that acoustic emission measured during the compressive straining of columnar and granular ice is consistent with the model for the lognormal dependence of the crack density on strain. Evidence is presented that the lognormal distribution may also provide a good description of the strain dependence of the dislocation density. 


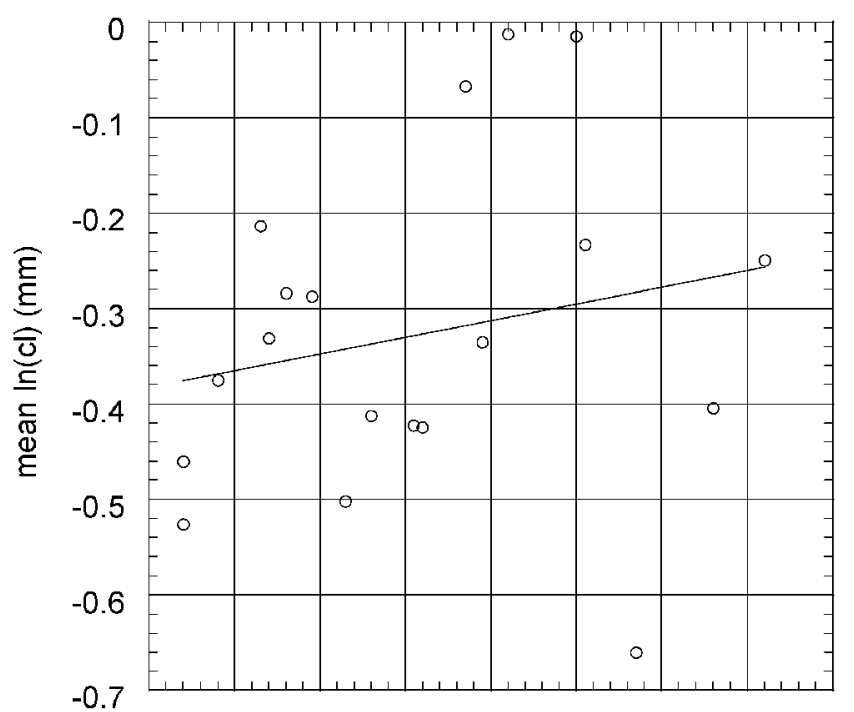

$\begin{array}{lllllllll}2 & 3 & 4 & 5 & 6 & 7 & 8 & 9 & 10\end{array}$

a

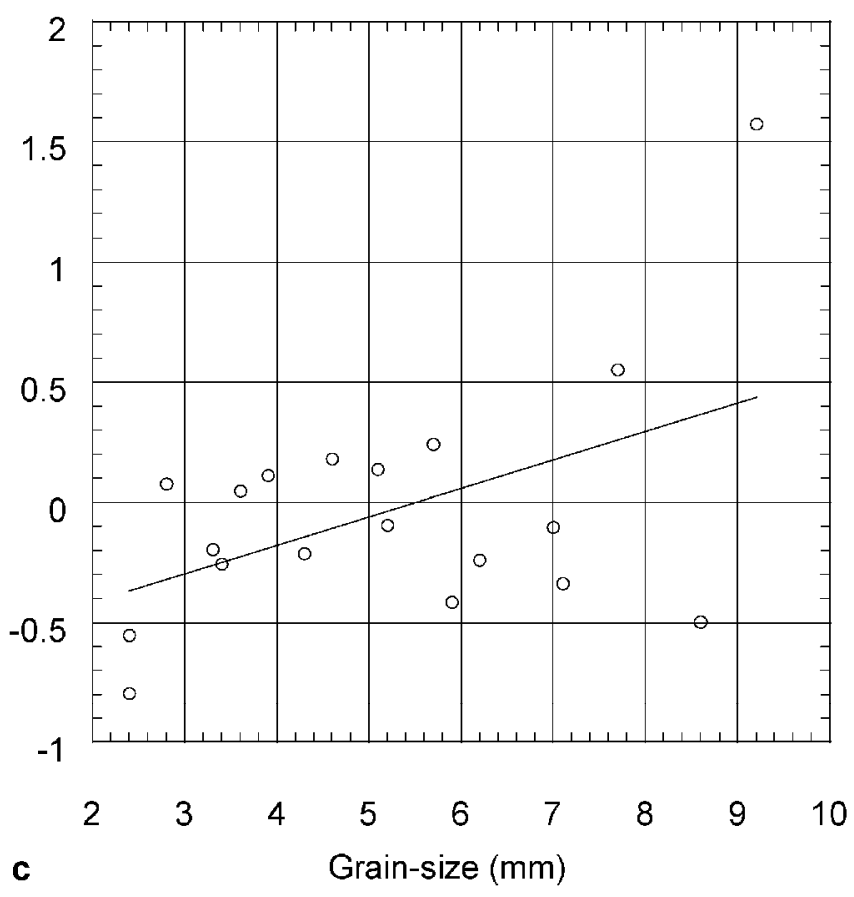

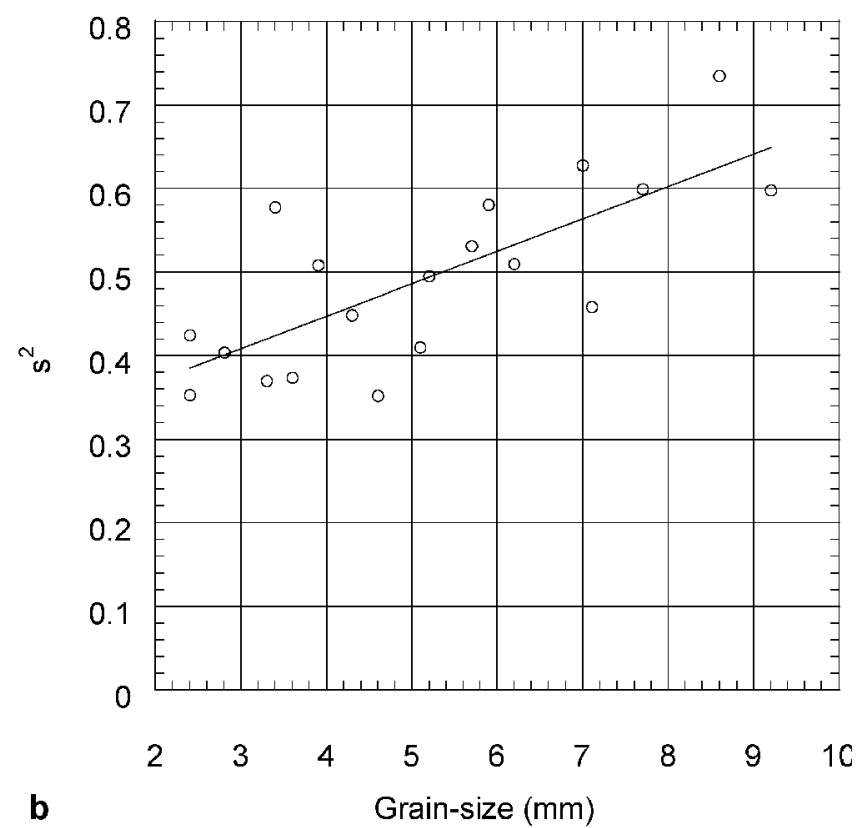

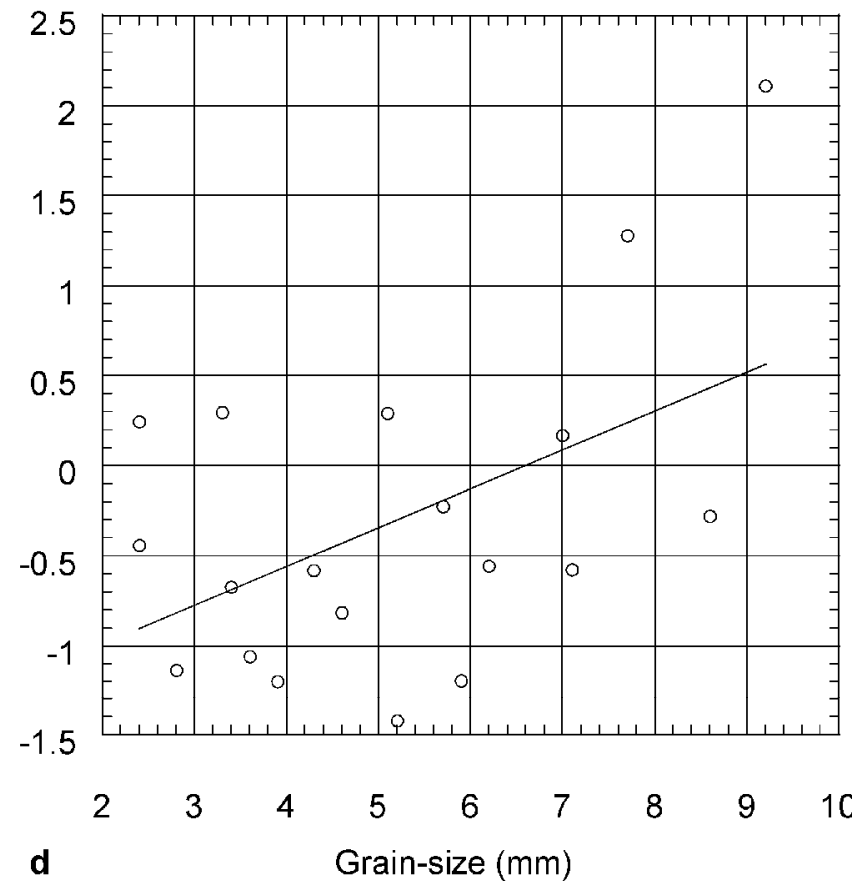

Fig. 1. Grain-size dependence of statistical characteristics for the crack-length populations induced in each specimen; nominal strain rate $=10^{-3} \mathrm{~s}^{-1}, \mathrm{~T}=-10^{\circ} \mathrm{C}$. The line in each plot is the linear least-squares fit to the data points. (a) Grain-size dependence of the mean of the logarithms of the crack lengths, $\overline{\ln (\mathrm{cl})}$. (b) Grain-size dependence of the variance, $s^{2}$. (c) Grain-size dependence of the skewness, $\gamma_{1}$. (d) Grain-size dependence of the excess, $\gamma_{2}$.

\section{STATISTICAL GHARACTERISTICS OF THE GRAGK-LENGTH POPULATIONS}

The observations on crack populations given in Gold (1997, 1999b) were made for rectangular specimens of average grain-size $2-9 \mathrm{~mm}$, subjected to constant nominal strain rates of $10^{-2}, 10^{-3}, 10^{-4}$ and $10^{-5} \mathrm{~s}^{-1}$ at temperatures of $-5^{\circ},-10^{\circ},-20^{\circ}$ and $-30^{\circ} \mathrm{C}$. The corresponding actual strain rates were $6.7 \times 10^{-3} \mathrm{~s}^{-1}, 7.6 \times 10^{-4} \mathrm{~s}^{-1}, 7.6 \times 10^{-5} \mathrm{~s}^{-1}$ and $7.8 \times 10^{-6} \mathrm{~s}^{-1}$. Maximum applied stresses were $3-5 \mathrm{MPa}$, depending on the strain rate and temperature. The maximum strains were between $4.1 \times 10^{-4}$ and $6.6 \times 10^{-4}$ for the nominal rates of $10^{-2}, 10^{-3}$ and $10^{-4} \mathrm{~s}^{-1}$, and between $4.2 \times 10^{-4}$ and $9.6 \times 10^{-4}$ for the nominal rate of $10^{-5} \mathrm{~s}^{-1}$. Observations on crack populations induced in specimens of grain-size about $3 \mathrm{~mm}$ and at various tempera- tures under constant-load conditions were reported earlier (Gold, 1972a, b). Details concerning preparation of the specimens, determination of the grain-size, application and measurement of the strains or loads, observation of the cracks and measurement of crack lengths are given in the cited papers. Only those observations made at a temperature of $-10^{\circ} \mathrm{C}$ for the constant-strain-rate tests and at $-9.5^{\circ} \mathrm{C}$ for the constantload tests are considered in this paper.

\subsection{Grain-boundary cracks}

A discrete statistical analysis was made of the grain-boundary crack lengths for each specimen to bring out possible limitations of the lognormal distribution as a descriptor of the crack-length populations. The number of cracks, $n$, 

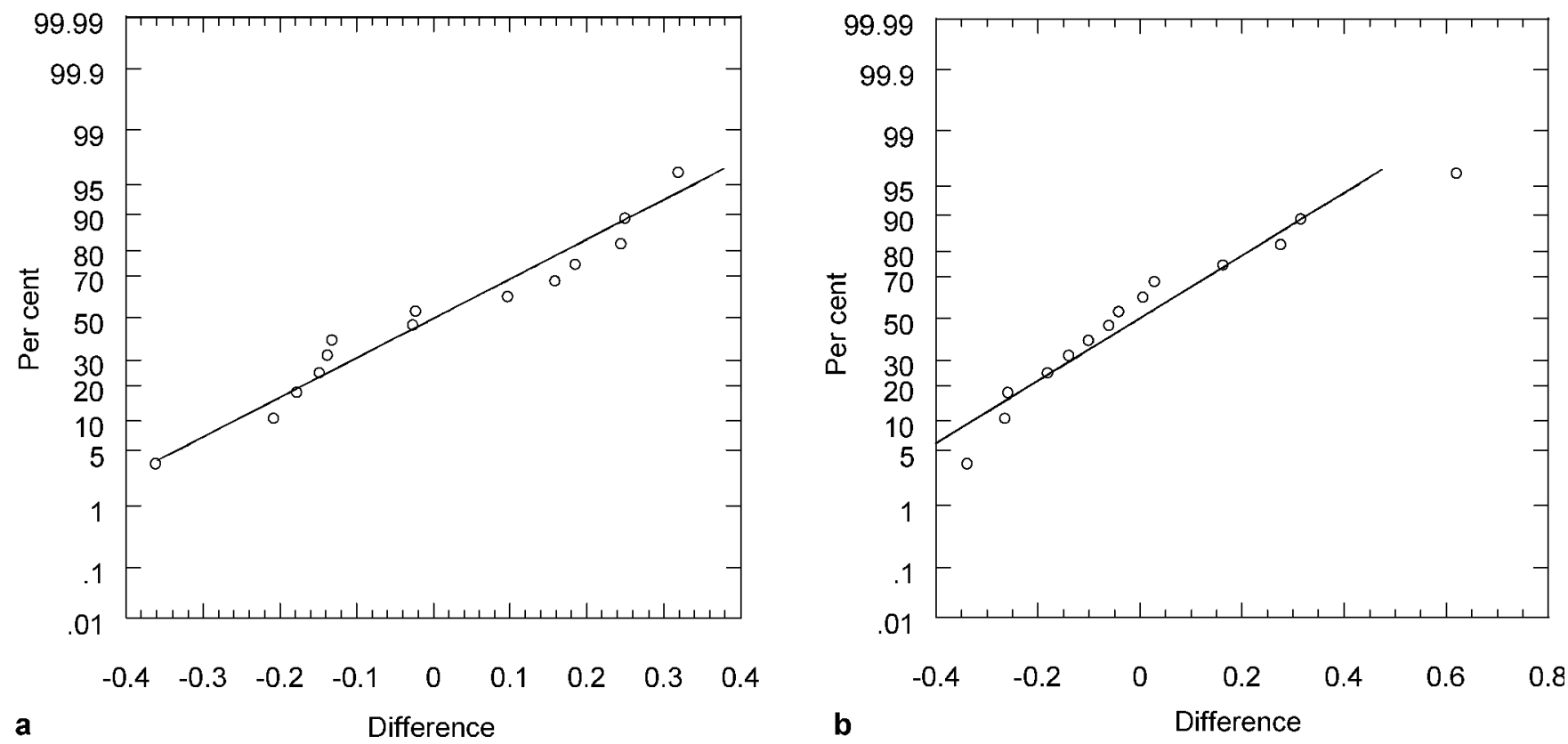

Fig. 2. Grain-size dependence of the difference between the specimen value of the statistical characteristic $\overline{\ln (\mathrm{cl})}$ or $s^{2}$ and the corresponding mean value for the specimen grain-size; nominal strain rate $=10^{-4} \mathrm{~s}, \mathrm{~T}=-10^{\circ} \mathrm{C}$. The line in each plot is the linear least-squares fit of the normal function to the difference. (a) $\overline{\ln (\mathrm{cl})}_{i}-\overline{\ln (\mathrm{cl})}_{\text {id }}$ for the ith specimen of grain-size d. (b) $s^{2}{ }_{i}-s^{2}{ }_{i d}$ for the ith specimen of grain-size $d$.
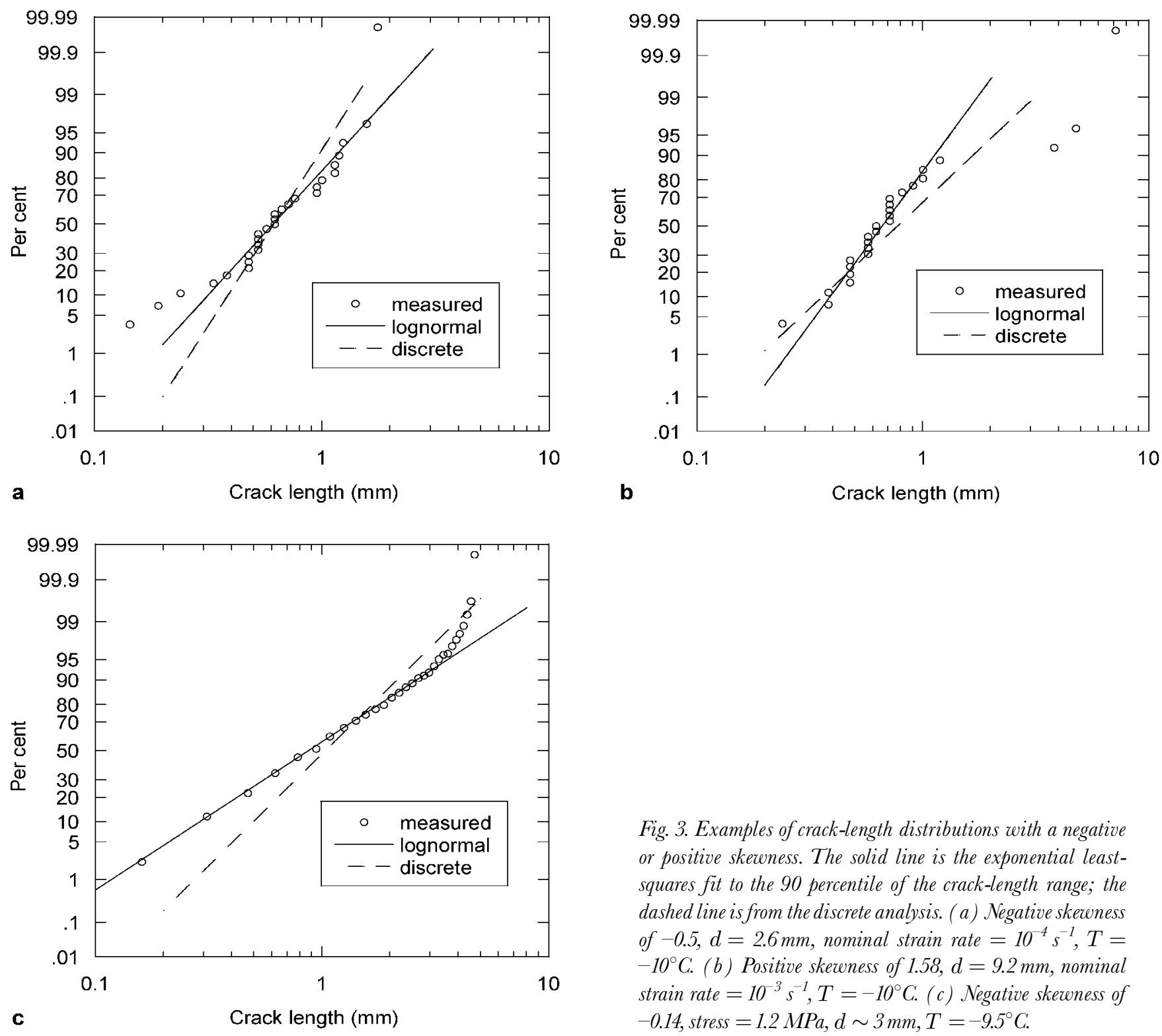

Fig. 3. Examples of crack-length distributions with a negative or positive skewness. The solid line is the exponential leastsquares fit to the 90 percentile of the crack-length range; the dashed line is from the discrete analysis. (a) Negative skewness of $-0.5, d=2.6 \mathrm{~mm}$, nominal strain rate $=10^{-4} \mathrm{~s}^{-1}, \mathrm{~T}=$ $-10^{\circ} \mathrm{C}$. (b) Positive skewness of $1.58, d=9.2 \mathrm{~mm}$, nominal strain rate $=10^{-3} \mathrm{~s}^{-1}, \mathrm{~T}=-10^{\circ} \mathrm{C}$. (c) Negative skewness of -0.14 , stress $=1.2 \mathrm{MPa}, d \sim 3 \mathrm{~mm}, \mathrm{~T}=-9.5^{\circ} \mathrm{C}$. 
mean of the natural logarithms of the crack lengths, $\overline{\ln (\mathrm{cl})}$, variance, $s^{2}$, skewness, $\gamma_{1}$, and excess, $\gamma_{2}$, of each population are given in Table 1 for the four strain rates. The skewness is a measure of the asymmetry of a distribution relative to a normal one and is given by:

$$
\gamma_{1}=\frac{1}{n} \frac{\sum_{i}\left[\ln (\mathrm{cl})_{i}-\overline{\ln (\mathrm{cl})}\right]^{3}}{s^{3}},
$$

where $\ln (\mathrm{cl})_{i}$ is the natural logarithm of crack length $i$, and $s$ is the specimen standard deviation. The coefficient of excess indicates whether a distribution is flatter or more peaked than a normal one and is given by:

$$
\gamma_{2}=\frac{1}{n} \frac{\sum_{i}\left[\ln (\mathrm{cl})_{i}-\overline{\ln (\mathrm{cl})}\right]^{4}}{s^{4}}-3 .
$$

For the normal curve, the skewness and excess are zero. A positive excess indicates a curve more peaked than the normal one.

Figure la presents the grain-size dependence of $\overline{\ln (\mathrm{cl})}$ for the nominal strain rate of $10^{-3} \mathrm{~s}^{-1}$. The line is the linear leastsquares fit to the observations. It indicates a tendency for the mean value to increase with increase in grain-size, but there is appreciable scatter and the correlation is correspondingly weak. The grain-size dependence for $\overline{\ln (\mathrm{cl})}$ is more apparent for the nominal rates of $10^{-4}$ and $10^{-5} \mathrm{~s}^{-1}$, and the scatter in the data points appreciably smaller. The dependence for the three rates is similar to that presented in Gold (1997) for the dependence of $\overline{\ln (\mathrm{cl})}$ on the natural logarithm of the grainsize.

Figure $1 \mathrm{~b}$ shows the grain-size dependence for the variance, $s^{2}$, at the nominal strain rate of $10^{-3} \mathrm{~s}^{-1}$. The line in the figure is the linear least-squares fit to the observations. The analysis indicates that the variance increases with increasing grain-size. The grain-size dependence for the skewness is shown in Figure lc and for the excess in Figure ld, for the same nominal strain rate. Figure lc and d indicate that both these statistical characteristics tend to increase from negative to positive values with increasing grain-size and to have the value associated with a normal population at the average grain-size of about $6 \mathrm{~mm}$. There were insufficient observations for large grain-size specimens and too great a scatter in values to show clearly the grain-size dependence of the variance, skewness and excess for the nominal rates of $10^{-4} \mathrm{~s}^{-1}$ and $10^{-5} \mathrm{~s}^{-1}$.

Assume that the parent population from which the specimens were drawn has a random distribution. If this is the case, statistical theory shows that, for each distribution characteristic given in Table 1 , the population formed by the difference between each specimen value and the mean value for the same grain-size will tend to have a normal distribution. These differences were determined for each set of characteristics in Table 1 and plotted on normal distribution coordinates. The mean value for a given specimen grain-size was determined from the linear least-squares fit for the plot of the characteristic against grain-size, as presented in Figure la-d.

Figure $2 \mathrm{a}$ presents the result for $\overline{\ln (\mathrm{cl})}$ for the nominal strain rate of $10^{-4} \mathrm{~s}^{-1}$, and Figure $2 \mathrm{~b}$ for the variance, $s^{2}$, for the same rate. The line in each plot was determined from a linear least-squares fit of the difference values to the corresponding percentage values. It can be seen that the normal distribution provides a good description for each of these differences in spite of insufficient large grain-size specimens and large scatter. In all cases, the correlation coefficient for the linear least-squares fit of the differences to the normal probability function was $>0.95$ (10 of the 12 were $>0.97$ ), indicating that the logarithms of the crack lengths are random variables.

Figure $3 \mathrm{a}$ is an example of a crack-length distribution with a negative skewness of -0.5 , and Figure $3 \mathrm{~b}$ of one with a positive skewness of 1.58. Figure $3 \mathrm{a}$ is for a specimen of mean grain-size $2.6 \mathrm{~mm}$, and Figure $3 \mathrm{~b}$ for a specimen of mean grain-size $9.2 \mathrm{~mm}$. For the negative skewness, the observations are above the line for the crack percentages of $<10 \%$ and $>95 \%$. For the positive skewness example, they are below the line for percentages $>90 \%$. Figure $3 \mathrm{c}$ presents the distribution for 576 cracks that formed during the straining of 21 specimens of mean grain-size of about $3 \mathrm{~mm}$ under a constant load of $1.2 \mathrm{MPa}$ (strain rate about $3.5 \times 10^{-7} \mathrm{~s}^{-1}$ ).

The percentages associated with the first two or three crack lengths can be quite variable. They are extreme values for the specimen distribution and are subject to the random variation expected for that situation. A similar argument could be made for crack lengths above the $90 \%$ level, as they also are extreme values for the distribution. The association of negative skewness with small grain-size, and positive with large grain-size, as shown in Figures $1 \mathrm{c}$ and $3 \mathrm{a}-\mathrm{c}$, suggests, however, that the length of the grain-boundary facet, and therefore the grain-size, may also affect crack length.

The exponential least-squares fit for the logarithm of the crack length to the corresponding percentage value was determined for the range 5-90\% for the three examples presented in Figure 3. The lower value of the range is the percentage of cracks of length less than or equal to the crack length at the $5 \%$ level, so these cracks are, in effect, included in the calculation. Cracks of length greater than that associated with the $90 \%$ level are not included. Shown for each plot are the lines determined from the exponential leastsquares fit and from the discrete analysis using all the crack lengths. The correlation coefficient for the lognormal fit over the $5-90 \%$ range for each of the specimens was $>0.95$. This analysis indicates that the distribution in the crack lengths is not fully lognormal, but the lognormal distribution function is a satisfactory description over the range of $5-90 \%$ of the population.

\subsection{Strain dependence of the mean and variance for the grain-boundary cracks}

Gold (1972a) measured the length of the grain-boundary cracks present at strains of 2, 4 and $7 \times 10^{-4}$ in a set of columnar-grain specimens. The specimens, of average grain-size $2-4 \mathrm{~mm}$, were strained at $-9.5^{\circ} \mathrm{C}$ by a constant uniaxial compressive stress of $1.2 \mathrm{MPa}$ applied perpendicular to the long direction of the grains. Cracks that formed in the ranges $0-2 \times 10^{-4}, 2-4 \times 10^{-4}$ and $4-7 \times 10^{-4}$ were marked with different colours during the tests so that they could be identified for the length measurements. Length measurements were also made on the cracks induced in a second set of specimens strained to $15 \times 10^{-4}$ under the same conditions of load and temperature. The results are presented on a lognormal plot in Figure 4. The lines shown are the exponential least squares fit of the crack lengths to the associated percentages. All crack lengths were included in the calculation for the specimens strained to $2 \times 10^{-4}$ and $4 \times 10^{-4}$, but only those up to and including the $95 \%$ percentile level for the other two strains.

Figure 5 shows the strain dependence of the logarithmic mean crack length (LMCL) and standard deviation. The mean increases almost linearly to the strain of $15 \times 10^{-4}$ for 


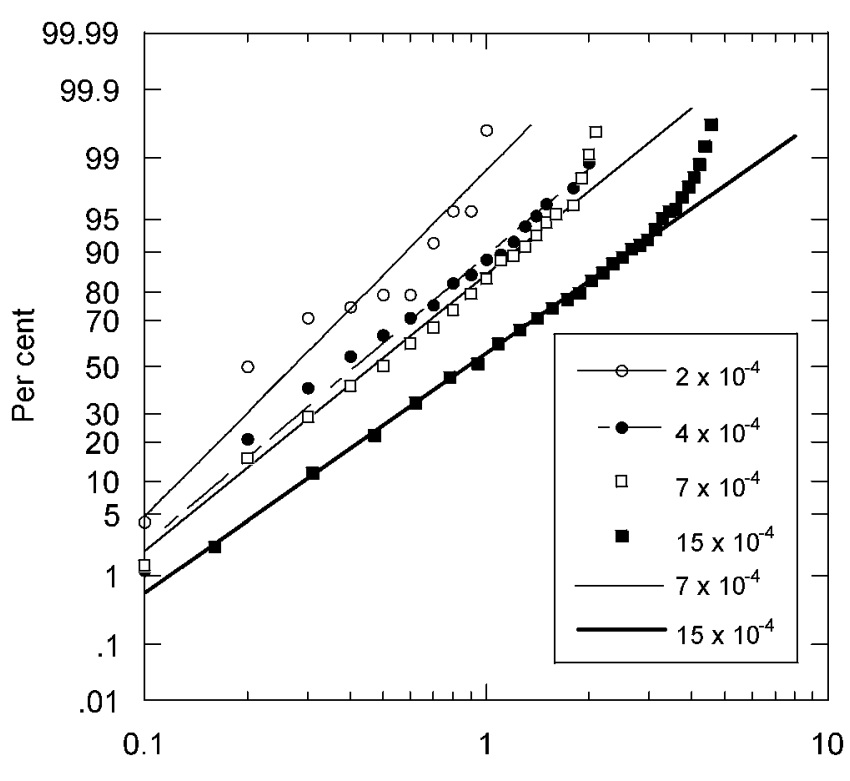

Crack length $(\mathrm{mm})$

Fig. 4. Lognormal plot of the crack-length distribution for the shown amount of strain. The lines give the exponential leastsquares dependence of the per cent of cracks on the logarithm of the crack length. All data points were used for the strains of $2 \times 10^{-4}$ and $4 \times 10^{-4}$, and those up to and including the 95 percentile of the crack lengths for the strains of $7 \times 10^{-4}$ and $15 \times 10^{-4}$; stress $=1.2 \mathrm{MPa}, 2<d<4 \mathrm{~mm}, \mathrm{~T}=-9.5^{\circ} \mathrm{C}$.

an imposed average strain rate of about $6.2 \times 10^{-7} \mathrm{~s}^{-1}$. This amount of strain is more than double that imposed in the constant-strain-rate tests. The standard deviation, assumed to be given by the slope of the lines in Figure 4, appears to tend to a limiting value with strain. Although these results are for one strain rate only, they do give some indication of the initial dependence on strain of two important statistical characteristics of the crack-length distributions.

\subsection{Transgranular cracks}

There were not sufficient transgranular cracks for an analysis as detailed as that for the grain-boundary cracks. The specimens were grouped for each nominal strain rate according to whether their mean grain-size was less than or greater than $5 \mathrm{~mm}$. Cracks with both a grain-boundary and a transgranular component were not included and are considered separately. The number of grain-boundary and transgranular cracks was determined for each crack length.

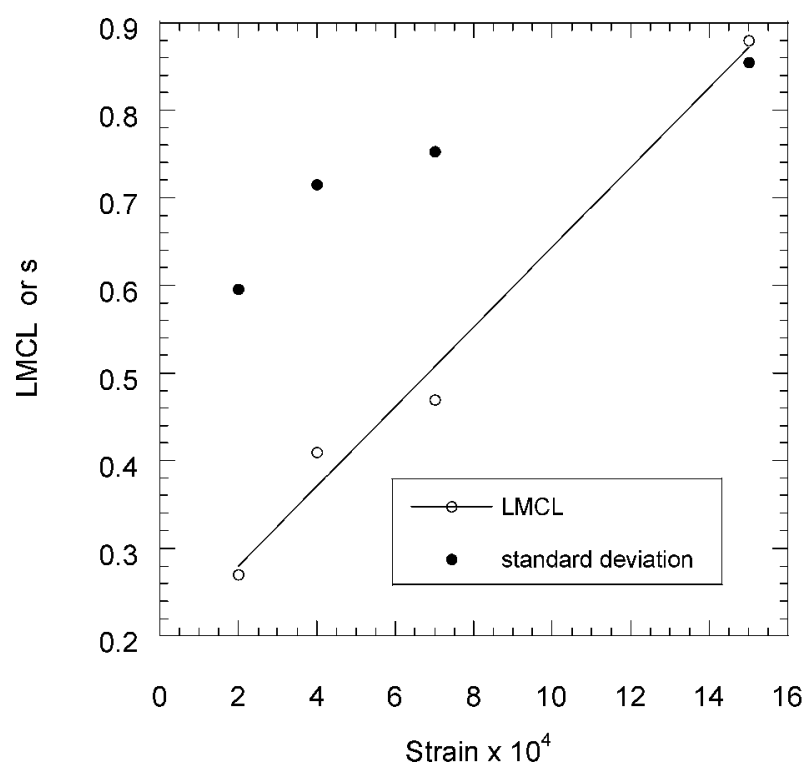

Fig. 5. Strain dependence of the logarithmic mean crack length ( LMCL $(\mathrm{mm})$ ) and standard deviation, $\mathrm{s}$, for the results presented in Figure 4.

The grain-boundary crack population was compared to the corresponding transgranular population for each strain rate and grain-size range using the analysis of variance (ANOVA) program in Microsoft Excel version 5. This program tests the hypothesis that the means of the two populations are equal. The results are presented in Table 2.

The criterion used in the test is the $F$ statistic. In its application, a critical value is selected that depends on the degrees of freedom for the calculation associated with each population and the confidence level desired. The value of $F$ calculated for each condition is presented in Table 2 along with the critical value of $F$ at the $95 \%$ confidence level. It can be seen that the value of $F$ for each condition is greater than the critical value, indicating that, at the $95 \%$ confidence level, the hypothesis that the means of the two populations are equal must be rejected. This conclusion is consistent with the two populations being associated with different crack-forming processes.

The fact that the populations are different does not mean that they are not correlated. The crack populations for each grain-size range were divided into groups in steps of $\ln (\mathrm{crl})=0.3$ for the constant-strain-rate tests and 0.2 for the tests carried out under a constant load of 1.2 MPa. Only those crack size ranges that had both grain-boundary $(\mathrm{gb})$

Table 2. Results of analysis of variation tests for the equality of the means of the grain-boundary and transgranular crack populations for the constant-strain-rate tests and constant-load tests for stress of $1.2 \mathrm{MPa}$; grain-size $<5 \mathrm{~mm}$ and $>5 \mathrm{~mm}$

\begin{tabular}{|c|c|c|c|c|c|c|c|c|c|c|c|c|}
\hline \multirow{3}{*}{$\begin{array}{c}\text { Strain rate } \\
\mathrm{s}^{-1}\end{array}$} & \multicolumn{6}{|c|}{ Grain-size range $<5 \mathrm{~mm}$} & \multicolumn{6}{|c|}{ Grain-size range $>5 \mathrm{~mm}$} \\
\hline & $n \mathrm{gb}$ & $n \operatorname{tr}$ & $\mathrm{df}$ & $F$ & $P$ & $F_{\text {crit }}$ & $n \mathrm{gb}$ & $n \operatorname{tr}$ & $\mathrm{df}$ & $F$ & $P$ & $F_{\text {crit }}$ \\
\hline & & & & & & & & & & & & \\
\hline $7.6 \times 10^{-4}$ & 312 & 23 & 1,17 & 8.41 & 0.01 & 4.45 & 265 & 33 & 1,22 & 6.83 & 0.02 & 4.30 \\
\hline $7.6 \times 10-5$ & 244 & 33 & 1,21 & 9.45 & 0.01 & 4.32 & 136 & 33 & 1,22 & 6.28 & 0.02 & 4.30 \\
\hline $7.8 \times 10^{-6}$ & 230 & 98 & 1,22 & 7.27 & 0.01 & 4.30 & 115 & 33 & 1,20 & 6.40 & 0.02 & 4.35 \\
\hline $6.2 \times 10-7$ & 144 & 68 & 1,24 & 7.54 & 0.01 & 4.26 & & & & & & \\
\hline
\end{tabular}

Notes: $F$ is the calculated value for the $F$ statistic, $P$ is the corresponding probability that the means are equal, $F_{\text {crit }}$ is the $F$ value for the $95 \%$ confidence level that the means are not equal, $\mathrm{df}$ is the degrees of freedom for the calculation of $F$, and $n$ is the number of cracks for each dataset. 
Table 3. Correlation between grain-boundary and transgranular cracks; $r$ is the correlation coefficient

(a)

\begin{tabular}{ccccccccc}
\hline Strain rate & \multicolumn{4}{c}{$d<5 \mathrm{~mm}$} & \multicolumn{5}{c}{$d>5 \mathrm{~mm}$} \\
& $\# \mathrm{gb}$ & $\# \mathrm{tr}$ & $\# \mathrm{cg}$ & $r$ & $\# \mathrm{gb}$ & $\# \mathrm{tr}$ & $\# \mathrm{cg}$ & $r$ \\
$\mathrm{~s}^{-1}$ & & & & & & & & \\
\hline $7.6 \times 10^{-4}$ & 221 & 22 & 6 & 0.84 & 230 & 33 & 9 & 0.90 \\
$7.6 \times 10^{-5}$ & 235 & 33 & 10 & 0.71 & 110 & 33 & 9 & 0.57 \\
$7.8 \times 10^{-6}$ & 224 & 96 & 10 & 0.88 & 102 & 33 & 9 & 0.69 \\
$6.2 \times 10^{-7}$ & 144 & 68 & 13 & 0.47 & & & &
\end{tabular}

(b)

Strain rate $\# \mathrm{gb}_{\mathrm{c}} \quad \# \mathrm{tr}_{\mathrm{c}} \quad r$

$\mathrm{s}^{-1}$

\begin{tabular}{llll}
$7.6 \times 10^{-4}$ & 25 & 25 & 0.30 \\
$7.6 \times 10^{-5}$ & 26 & 26 & 0.17 \\
$7.8 \times 10^{-6}$ & 54 & 54 & 0.13 \\
\hline
\end{tabular}

Notes: (a) Correlation between fully grain-boundary and transgranular cracks. The cracks are grouped in steps of $\ln (\mathrm{crl})$ of 0.3 for the constantstrain-rate tests and 0.2 for the tests under a constant load of $1.2 \mathrm{MPa}$ (strain rate $\approx 6.2 \times 10^{-7} \mathrm{~s}^{-1}$ ); $\# \mathrm{gb}$ is the number of grain-boundary cracks, \#tr the number of transgranular cracks and \#cg the number of groups. (b) Correlation, for each constant-strain-rate condition, between the grain-boundary component and the associated transgranular component, for the combined grain-boundary-transgranularcracks.

and transgranular (tr) cracks could be used in the analysis. The correlation coefficient, $r$, for the grain boundary and transgranular crack populations is given by:

$$
r=\frac{\sum_{i}\left(n_{\mathrm{gb} i}-\overline{n_{\mathrm{gb}}}\right)\left(n_{\mathrm{tr} i}-\overline{n_{\mathrm{tr}}}\right)}{(n-1) s_{\mathrm{gb}} s_{\mathrm{tr}}},
$$

where $n_{\mathrm{gb} i}$ is the number of grain-boundary cracks in crack length range, $i, n_{\operatorname{tr} i}$ is the number of transgranular cracks, the barred terms are the mean values based on the number of groups, $s_{\mathrm{gb}}$ and $s_{\mathrm{tr}}$ are the corresponding standard deviations and $n$ is the number of groups.

The correlation coefficient for each grain-size range and strain rate is given in Table $3 \mathrm{a}$, along with the number of grain-boundary cracks, transgranular cracks and crack groups. There is a significant correlation between the number of grain-boundary cracks in a crack length range and the associated number of transgranular cracks, particularly for the higher strain rate. This might be expected if the strain energy for crack formation comes from two components of the internal strain-energy distribution (e.g. one associated with the relative movement between grains (grain-boundary cracks) and the second associated with the change in shape of the grains due to shear (transgranular cracks)). The tendency for a decreasing correlation coefficient with decreasing strain rate is associated with a corresponding increase in the relative proportion of transgranular cracks from about zero for high strain rates to about $25 \%$ for low strain rates (Gold, 1997).

\subsection{Combined grain-boundary and transgranular cracks}

There were not enough combined grain-boundary and transgranular cracks for a statistical analysis using the same grainsize grouping as that for the transgranular cracks. These cracks were listed for all grain-sizes for each strain rate and separated into their grain-boundary $\left(\mathrm{gb}_{\mathrm{c}}\right)$ and transgranular $\left(\operatorname{tr}_{\mathrm{c}}\right)$ components. Table $3 \mathrm{~b}$ presents the correlation coefficient for the crack pairs for each condition. It shows that the two populations, $\mathrm{gb}_{\mathrm{c}}$ and $\mathrm{tr}_{\mathrm{c}}$, are only weakly correlated and that the correlation decreases with decreasing strain rate.

The populations, $g \mathrm{~b}, \mathrm{tr}, \mathrm{gb}_{\mathrm{c}}$ and $\mathrm{tr}_{\mathrm{c}}$, for each strain rate and all crack lengths, were grouped in steps of $\ln (\mathrm{crl})=0.3$; $\mathrm{gb}$ and tr are the respective crack-length populations without the combined cracks. An ANOVA calculation was carried out on the six pairs gb, tr; $\mathrm{gb}_{\mathrm{c}}, \mathrm{tr}_{\mathrm{c}} ; \mathrm{gb}_{\mathrm{c}}, \mathrm{gb} ; \mathrm{gb}_{\mathrm{c}}, \mathrm{tr}$; $\operatorname{tr}_{\mathrm{c}}, \mathrm{gb} ; \mathrm{tr}_{\mathrm{c}}, \mathrm{tr}$ for each strain rate. The results are presented in Table 4. They show that the assumption of equality of the mean values for the populations in the pairs $\mathrm{gb}_{\mathrm{c}}, \operatorname{tr}_{\mathrm{c}} ; \mathrm{gb}_{\mathrm{c}}, \mathrm{tr}$; and $\operatorname{tr}_{\mathrm{c}}, \operatorname{tr}$, cannot be rejected at the $95 \%$ confidence level.

Table 4. Analysis of variation for the total of all grain-boundary, transgranular and combined grain-boundary/transgranular cracks for all specimens for each of the constant-strain-rate conditions

\begin{tabular}{|c|c|c|c|c|c|c|c|c|c|c|c|c|c|}
\hline $\begin{array}{c}\text { Strain rate } \\
\mathrm{s}^{-1}\end{array}$ & \multicolumn{2}{|c|}{ Number of cracks } & df & $F$ & $P$ & $F_{\text {crit }}$ & \multirow{2}{*}{$\begin{array}{c}\text { Strain rate } \\
\mathrm{s}^{-1}\end{array}$} & \multicolumn{2}{|c|}{ Number of cracks } & \multirow[t]{2}{*}{ df } & \multirow[t]{2}{*}{$F$} & \multirow[t]{2}{*}{$P$} & \multirow[t]{2}{*}{$F_{\text {crit }}$} \\
\hline & $\# \mathrm{gb}$ & $\# \operatorname{tr}$ & & & & & & $\# \mathrm{gb}_{\mathrm{c}}$ & \#tr & & & & \\
\hline $7.6 \times 10^{-4}$ & 577 & 56 & 1,23 & 7.91 & 0.010 & 4.28 & $7.6 \times 10^{-4}$ & 25 & 56 & 1,17 & 2.43 & 0.137 & 4.45 \\
\hline $7.6 \times 10^{-5}$ & 380 & 66 & 1,23 & 7.15 & 0.014 & 4.28 & $7.6 \times 10^{-5}$ & 26 & 66 & 1,15 & 2.01 & 0.178 & 4.54 \\
\hline $7.8 \times 10^{-6}$ & 345 & 131 & 1,25 & 6.91 & 0.014 & 4.24 & $7.8 \times 10^{-6}$ & 54 & 131 & 1,22 & 3.91 & 0.061 & 4.30 \\
\hline $7.6 \times 10^{-4}$ & $\begin{array}{c}\# \mathrm{gb}_{\mathrm{c}} \\
25\end{array}$ & $\begin{array}{c}\# \operatorname{tr}_{\mathrm{c}} \\
25\end{array}$ & 1,16 & 0 & 1 & 4.49 & $7.6 \times 10^{-4}$ & $\begin{array}{c}\# \operatorname{tr}_{\mathrm{c}} \\
25\end{array}$ & $\begin{array}{c}\# \mathrm{gb} \\
577\end{array}$ & 1,22 & 8.46 & 0.008 & 4.30 \\
\hline $7.6 \times 10^{-5}$ & 26 & 26 & 1,13 & 0.12 & 0.73 & 4.67 & $7.6 \times 10^{-5}$ & 26 & 380 & 1,21 & 8.09 & 0.01 & 4.32 \\
\hline $7.8 \times 10^{-6}$ & 54 & 54 & 1,19 & 0.18 & 0.68 & 4.38 & $7.8 \times 10^{-6}$ & 54 & 345 & 1,22 & 10.77 & 0.003 & 4.30 \\
\hline $7.6 \times 10^{-4}$ & $\begin{array}{c}\# \mathrm{gb}_{\mathrm{c}} \\
25\end{array}$ & $\begin{array}{c}\# \mathrm{gb} \\
577\end{array}$ & 1,22 & 8.46 & 0.008 & 4.30 & $7.6 \times 10^{-4}$ & $\begin{array}{c}\# \operatorname{tr}_{\mathrm{c}} \\
25\end{array}$ & $\begin{array}{c}\# \operatorname{tr} \\
56\end{array}$ & 1,17 & 2.45 & 0.136 & 4.45 \\
\hline $7.6 \times 10^{-5}$ & 26 & 380 & 1,20 & 6.75 & 0.017 & 4.35 & $7.6 \times 10^{-5}$ & 26 & 66 & 1,16 & 3.22 & 0.092 & 4.49 \\
\hline $7.8 \times 10^{-6}$ & 54 & 345 & 1,23 & 12.38 & 0.002 & 4.28 & $7.8 \times 10^{-6}$ & 54 & 131 & 1,21 & 3.04 & 0.096 & 4.32 \\
\hline
\end{tabular}

Notes: \#gb is the number of grain-boundary cracks, \#tr is the number of transgranular cracks, \#gb is the number of grain-boundary cracks for the combined grain-boundary and transgranular cracks, \# $\operatorname{tr}_{\mathrm{c}}$ is the associated number of transgranular cracks, df is the degrees of freedom for the calculation of the $F$ statistic, $P$ is the probability associated with $F$, and $F_{\text {crit }}$ is the value for $F$ at the $95 \%$ confidence level. The cracks in each population were grouped in steps of $\ln (\mathrm{crl})=0.3$. 
At the same confidence level, the equality of the means for the populations in the pairs $\mathrm{gb}, \mathrm{tr} ; \mathrm{gb}_{\mathrm{c}}, \mathrm{gb}$; and $\mathrm{tr}_{\mathrm{c}}, \mathrm{gb}$ is rejected. This indicates that the grain-boundary component of the combined grain-boundary-transgranularcrack populations is associated primarily with the corresponding transgranular populations, and therefore with the component of the internal strain energy that is associated with the formation of transgranular cracks.

The foregoing analyses supports the hypothesis that, for the conditions of the experiments, the development of grain-boundary and transgranular crack populations is a random process for strains to at least $60 \%$ of that for brittle failure and greater than that for ductile behaviour. They can be thought of as the primary crack population, as they serve as precursors to failure by fracture and the crack-extension mechanisms associated with it. A statistical model for the crack length for these populations is presented in the following section, along with a statistical model for the strain dependence of the crack density. Both models are based on the assumption that a change in the random variable of a population is proportional to the population value of the variable at the time of the change. As the occurrence of each random event can be considered as an impulse change to the population, this process will be referred to as "impulse proportionate change".

\section{STATISTICAL MODELS OF BEHAVIOUR}

For the columnar-grain ice and direction of application of the loads used in the tests, it would be expected that local stresses would be induced at grain boundaries and in the grains, due, for example, to grain-boundary shear, grain distortion and dislocation mechanisms. These stresses would depend on the strain, strain rate, time, temperature and the relative crystallographic orientation of adjacent grains. It would be expected that they would be felt only to distances of the scale of grain-size and would not be affected significantly by the stress concentrations induced in more distant grains. They would depend on the relative orientation of neighbouring grains, as the change in shape of a grain must conform to the change in shape of all grains in contact with its boundaries (Tvergaard and Hutchinson, 1988).

Because the axis of symmetry of each grain is randomly oriented in the plane perpendicular to the long direction of the grains, there must be an equal probability for the occurrence of all possible combinations of crystallographic orientation of adjacent grains. Singularities that induce local stress fields can also be expected to be random in strength and location. This randomness of crystallographic orientation and of existing and potential stress singularities is built into the ice at the time it is made. It would seem reasonable to assume that, during a test, the combination of random crystallographic orientation and random stress singularities would result in a statistically variable internal strain-energy density.

The occurrence of a crack is a visible manifestation of the conditions required for its initiation. It would remove the initiating singularity, and a relatively large proportion of the associated strain energy would be used for its formation. From this point of view, the constant-load and constantstrain-rate tests provide a means of sampling the distribution in the internal strain energy available for crack formation, at least to the extent that crack length is a reasonable measure of the energy associated with a crack nucleating singularity. $\mathrm{Also}$, if the formation of a crack is an independent random event, each test can be considered as a concurrent set of independent observations of these events for the same external load conditions. This independence and randomness is assumed for the theoretical basis for the statistical behaviour of the crack length and for the strain dependence of the crack density.

The formation of a crack can be considered as an impulse decrease in the internal strain energy or impulse change in the crack population. It would seem reasonable to assume that the probability for its formation would depend on the strain energy density induced by the singularity at the site where it forms. Statistical models, based on impulse proportionate change, have found significant application in biology, small-particle statistics and other subject areas (Cramér, 1966; Aitchison and Brown, 1969). Such a model is the basis for the derivations given below.

\subsection{Grack length}

Assume the long narrow cracks formed in a specimen during a test are joined in sequence, edge to edge, in ascending order of crack length. Let the total length of joined cracks be divided into consecutive segments and the length up to and including the $\nu$ th segment be $C_{\nu}$. Consider the segment $C_{\nu}-C_{\nu-1}$. The number of cracks in it, $n_{\nu}$, is given by:

$$
n_{\nu}=\frac{C_{\nu}-C_{\nu-1}}{c_{\nu}}=\frac{\Delta C_{\nu}}{c_{\nu}}
$$

where $c_{\nu}$ is the mean crack length for the interval. The probability, $p_{\nu}$, of $n_{\nu}$ cracks of mean length $c_{\nu}$ forming in the interval is:

$$
p_{\nu}=\frac{n_{\nu}}{n_{\varepsilon}}=\frac{1}{n_{\varepsilon}} \frac{\Delta C_{\nu}}{c_{\nu}},
$$

where $n_{\varepsilon}$ is the total number of cracks that have formed in strain $\varepsilon$. Equation (5) has a one-to-one correspondence with the frequency distribution curve giving the probability of $n_{\nu}$ cracks of mean length $c_{\nu}$ forming in the interval $\Delta C_{\nu}$.

Let the crack-length change segments, $\Delta C_{\nu}$, be random variables and adjusted so that each contains only one crack, and let $\Delta C_{\nu} / n_{\varepsilon}=\Delta c_{\nu}$. Each segment is now divided into $n_{\varepsilon}$ sub-segments, each with the probability of $1 / n_{\varepsilon}$ for a crack to form in it. Substituting for $\Delta C_{\nu} / n_{\varepsilon}$ in Equation (5), the probability of a crack of mean length $c_{\nu}$ forming in one of the sub-segments of $\Delta C_{\nu}$ is $p_{\nu}=\Delta c_{\nu} / c_{\nu}$. Applying this to the distribution curve presentation of crack length, the probability that a crack will have a length equal to or less than $c_{\nu}$ is given by:

$$
p_{1}+p_{2}+\ldots+p_{\nu}=\sum_{\nu=1}^{\nu} \frac{\Delta c_{\nu}}{c_{\nu}} .
$$

With increasing number of cracks, Equation (6) is given approximately by:

$$
p_{1}+p_{2}+\ldots+p_{\nu}=\int_{c_{1}}^{c_{\nu}} \frac{\mathrm{d} c}{c} .
$$

As the $p_{\nu}$ are independent random variables, Equation (7) satisfies the conditions for the central limit theorem (Cramér, 1966, p. 220), and the probability density function for $p_{c}$ (the 


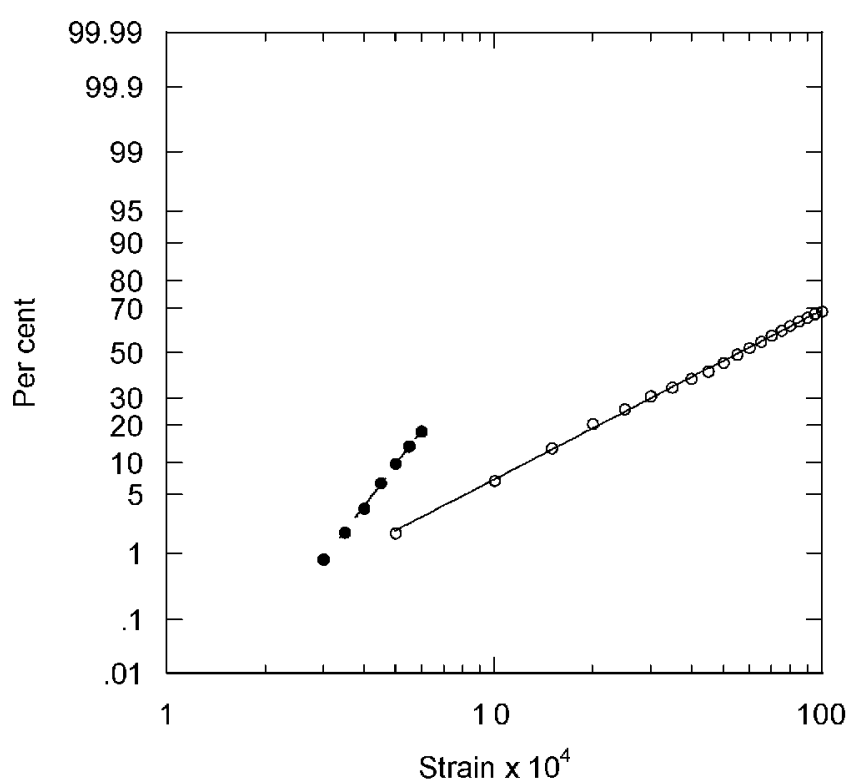

Fig. 6. Lognormal plot of the strain dependence of the normalized crack density, $n_{\varepsilon} / N_{0} \%$. The solid symbols are for specimens strained at the nominal rate of $10^{-4} \mathrm{~s}^{-1}, 2<d<4 \mathrm{~mm}, \mathrm{~T}=$ $-10^{\circ} \mathrm{C}, m_{\varepsilon}=9.07 \times 10^{-4}, \mathrm{~s}=0.46$; the open symbols are for specimens subjected to a constant load of $1.2 \mathrm{MPa}, d \sim 3 \mathrm{~mm}$, $T=-9.5^{\circ} \mathrm{C}, m_{\varepsilon}=55.7 \times 10^{-4}, \mathrm{~s}=1.17$.

probability that a crack will have a length $c$ ) is given by the lognormal distribution function:

$$
p_{c}=\frac{1}{\sigma\left(c-c_{1}\right) \sqrt{2 \pi}} \mathrm{e}^{\frac{\left[\ln \left(c-c_{1}\right)-\left.m_{c}\right|^{2}\right.}{2 \sigma^{2}}},
$$

where $m_{c}$ is the mean $\ln (c), \sigma$ the standard deviation and $c_{1}$ the length of the first crack.

\subsection{Strain dependence of the crack density}

It was shown in Gold (1999) that the lognormal distribution function was also a satisfactory description of the strain dependence of the crack density. The crack density for columnar-grain ice is defined as the number of cracks per unit area passing through the mid-plane of a specimen. The formation of a crack causes a step decrease in the total internal strain energy and a step change in the statistical characteristics of the crack population. Let the internal strain energy at strain $\varepsilon_{\nu}$ be $U_{\nu}=k \varepsilon_{\nu}^{2}$, where $k$ is a constant that depends on the elastic moduli. The change in strain energy at strain $\varepsilon_{\nu}$ due to a change in strain of $\Delta \varepsilon_{\nu}$ is given by:

$$
\Delta U_{\nu}=2 k \varepsilon_{\nu} \Delta \varepsilon_{\nu} .
$$

Let the probable change in strain energy due to a crack formed at strain $\varepsilon_{\nu}$ be $p_{u \nu} U_{\nu}$, where $p_{u \nu}$ is an independent random variable.

$$
p_{u \nu} U_{\nu}=p_{u \nu} k \varepsilon_{\nu}^{2}=2 k \varepsilon_{\nu} \Delta \varepsilon_{\nu},
$$

where $\Delta \varepsilon_{\nu}$ is now the probable change in strain due to the formation of the crack. From Equation (10):

$$
p_{u \nu}=\frac{2 \Delta \varepsilon_{\nu}}{\varepsilon_{\nu}} .
$$

As each impulse change of strain energy is associated with the formation of a crack, $\Delta \varepsilon_{\nu} / \varepsilon_{\nu}$ must be the probability, $p_{c \nu}$, for a crack to form at strain $\varepsilon_{\nu}$. The change in strain, $\Delta \varepsilon_{\nu}$, is an independent random variable.

Let the strain be divided into consecutive segments such that one crack is formed in each segment and let $N_{0}$ be the maximum crack density for the distribution. The proportion of the maximum crack density, $n_{\varepsilon} / N_{0}$, formed in strain $\varepsilon_{\nu}$, is given by:

$$
p_{c 1}+p_{c 2}+\ldots+p_{c n}=\sum_{\nu=1}^{n} \frac{\Delta \varepsilon_{\nu}}{\varepsilon_{\nu}} .
$$

With increasing number of cracks, Equation (12) is given approximately by:

$$
p_{c 1}+p_{c 2}+\ldots+p_{c n}=\int_{\varepsilon_{1}}^{\varepsilon_{n}} \frac{\mathrm{d} \varepsilon}{\varepsilon} .
$$

As the $p_{c n}$ are independent random variables, Equation (13) satisfies the conditions for the central limit theorem, and the probability density function for $p_{c \varepsilon}$ (the probability that a crack will form at strain $\varepsilon$ ) is given by:

$$
p_{c \varepsilon}=\frac{1}{\sigma\left(\varepsilon-\varepsilon_{1}\right) \sqrt{2 \pi}} \mathrm{e}^{\frac{\left[\mathrm{ln}\left(\varepsilon-\varepsilon_{1}\right)-m_{\varepsilon}\right]^{2}}{2 \sigma^{2}}},
$$

where $\varepsilon_{1}$ is the strain at which the first crack forms, $m_{\varepsilon}$ is the mean $\ln (\varepsilon)$ for the crack population, and $\sigma$ the standard deviation (a measure of the total strain over which the population forms).

Figure 6 presents the strain dependence of the normalized crack density, $n_{\varepsilon} / N_{0}$ in per cent, for two crack populations, plotted on lognormal probability coordinates. One of the examples is from the constant-load test series (Gold 1972b), for which the rate at which cracks formed, after a maximum, tended to zero with strain and $N_{0}$ could be easily determined from the observations. For the constant-strainrate experiments (Gold 1999b), the rate of strain was sufficiently high that the specimens would have failed in a brittle manner after a relatively small strain. To prevent this, the maximum stress was limited to about $60 \%$ of the stress to cause failure for the conditions of the test. For these experiments, $N_{0}$ is the maximum number of cracks that would have formed if the ice could have been strained without failing. It was assumed to be the value that gave the maximum correlation coefficient for an exponential curve fit of the percentage number of cracks to the logarithm of the strain. It can be seen in Figure 6 that the lognormal probability function provides a good description of the strain dependence of the crack density. The correlation coefficient was $>0.99$ for all the 15 datasets in Gold (1999b), and the maximum crack densities and logarithmic mean strains were found to depend in a consistent way on strain rate and grain-size.

\section{OTHER APPLICATIONS OF THE STRAIN- DEPENDENT MODEL}

\subsection{Acoustic emission}

Acoustic emission can be expected if impulse changes in structure generate elastic waves. Assuming the probability for this is proportional to the internal strain energy at an initiating singularity would result in the same statistical model as obtained for the strain dependence of the crack density. Gold (1960) measured the time and strain dependence of the acoustic emission for rectangular, columnargrain, specimens, $50 \times 100 \times 200 \mathrm{~mm}^{3}$, when subjected to a constant uniaxial compressive stress of $0.9-1.7 \mathrm{MPa}$ at a temperature of $-10^{\circ} \mathrm{C}$. The specimens were made from ice of average grain-size $<4.7 \mathrm{~mm}$. St. Lawrence and Cole (1982) 


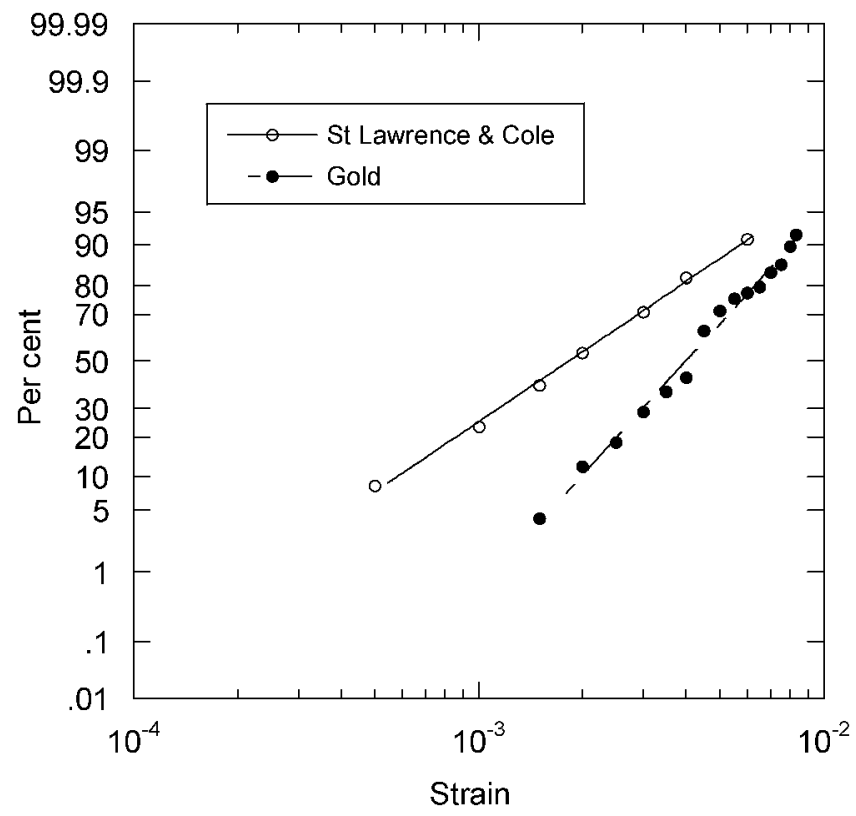

Fig. 7. Lognormal plot of the strain dependence of the acoustic emission density distribution (\% of the estimated maximum value). St. Lawrence and Cole (1982): granular ice; constant stress $=2.0 \mathrm{MPa}, d=1.2 \mathrm{~mm}, \mathrm{~T}=-5^{\circ} \mathrm{C}$. Gold (1960): columnar-grain ice; constant stress $=1.0 \mathrm{MPa}, d<4.7 \mathrm{~mm}$, $T=-10^{\circ} \mathrm{C}$

carried out similar measurements at $-5^{\circ} \mathrm{C}$ on cylindrical granular ice specimens, with $25.4 \mathrm{~mm}$ radius and $127 \mathrm{~mm}$ long, of average grain-size $1.2 \mathrm{~mm}$. In the case of Gold (1960), the strain dependence of the emission for constant stress was obtained from the original data. For St. Lawrence and Cole (1982), it was obtained from their figure 7 for stresses of 0.8 , $1.54,1.84,2.00,2.35,3.26$ and $3.67 \mathrm{MPa}$.

The emission density at given strains (number of counts per $\mathrm{m}^{2}$ for Gold (1960) and per $\mathrm{m}^{3}$ for St. Lawrence and Cole (1982)) was divided by the estimated maximum density, $N_{0}$, and plotted as a percentage against strain on lognormal coordinates. $N_{0}$ was varied until the correlation coefficient for a least-squares exponential fit of per cent of total emission to the corresponding logarithm of the strain was a maximum. Figure 7 gives an example of a lognormal fit from St. Lawrence and Cole (1982) and from Gold (1960).

The logarithmic mean strain, standard deviation, correlation coefficient and value of $N_{0}$ for each test are presented in Table 5. The analysis indicates that the lognormal distribution provides a satisfactory description of the strain dependence of the acoustic emission density. Figure 8 gives the stress dependence of the estimated values for $N_{0}$. The values of $N_{0}$ obtained for the granular ice were raised to the power of $2 / 3$ to make them comparable with the values obtained for the columnar-grain ice.

The stress dependence for the maximum crack densities determined for the same range of stress, given in table 1 of Gold (1999b), are also shown in Figure 8. It is of interest that the maximum densities for the acoustic emission for stress greater than about 1.4 MPa are about the same as those for the crack densities and less for stress less than that value. The densities from St. Lawrence and Cole (1982) are generally lower and this could be due, in part, to the higher temperature for their work and the smaller specimen grain-size. It has been observed for the constant-load tests at low stress (Gold, unpublished information) that cracks sometimes
Table 5. Defining characteristics for the strain dependence of the total number of acoustic emission events for ice subject to a constant compressive stress

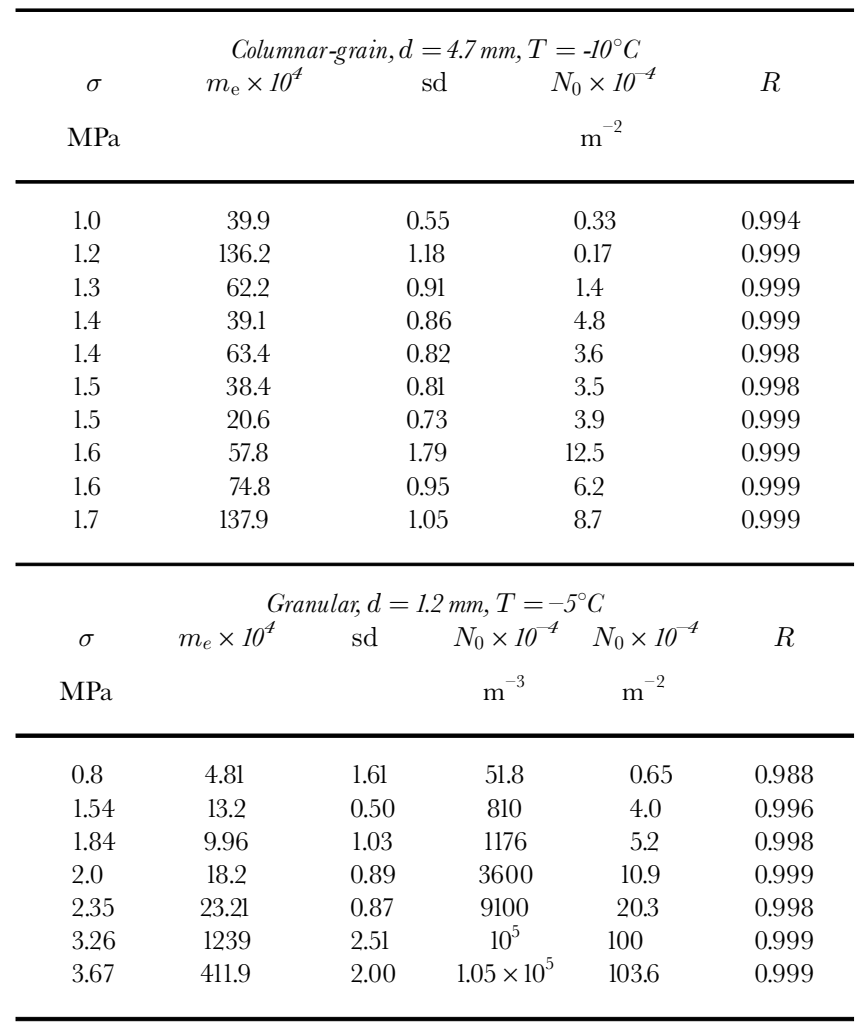

Notes: The characteristics were obtained from the least-squares exponential fit for a lognormal normal display of per cent of maximum number of events against strain. $\sigma$ is the stress, $N_{0}$ the maximum number of events $\left(\mathrm{m}^{-2}\right.$ for columnar-grain ice and $\mathrm{m}^{-3}$ for granular ice), $m_{\mathrm{e}}$ the logarithmic mean strain, sd the standard deviation, $d$ the average grain-size and $R$ the correlation coefficient.

formed slowly by the coalescence of voids and so would not be expected to emit an acoustic wave. This would also contribute to lowering the average emission density at the lower strain rates.

One of the difficulties in measuring the acoustic emission density is recording only emissions from a volume in which it is uniform. Gold (1972a) showed that edge and end effects had to be taken into consideration when determining the average crack density. Similar edge and end effects would be expected for acoustic emission. The sensors used by Gold (1960) and by St. Lawrence and Cole (1982) detected all the acoustic events for each specimen. This would cause the average to be lower than if it were calculated for a region free of these effects, but the form of the dependence of the acoustic emission on strain should not be affected.

Another difficulty is choosing the proper sensitivity and frequency range for the sensors to detect only the acoustic emission from the formation of cracks and not from noncrack-forming processes that emit elastic waves. The sensors used by Gold (1960) and St. Lawrence and Cole (1982) were probably not sufficiently sensitive to have been affected by this difficulty.

\subsection{Dislocation density}

Some models for crack initiation assume it is caused by dislocation processes either in the grain boundaries (grainboundary cracks) or within the grains (transgranular cracks). As the formation of a crack and the associated 


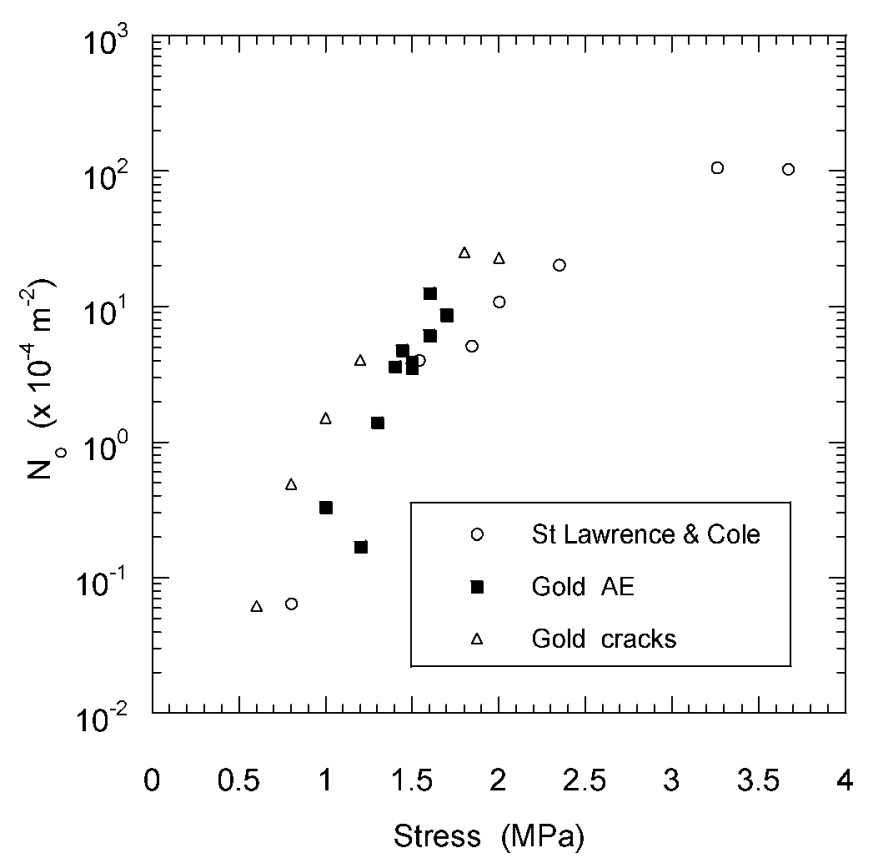

Fig. 8. Stress dependence of the maximum acoustic emission density. Open circles: St. Lawrence and Cole (1982) (granular ice; $\left.d=1.2 \mathrm{~mm}, T=-5^{\circ} \mathrm{C}\right)$; solid squares: Gold (1960) (columnar-grain ice; $d<4.7 \mathrm{~mm}, T=-10^{\circ} \mathrm{C}$ ); open triangles: Gold (1960) (maximum crack density; columnar-grain ice; $d \sim 3 \mathrm{~mm}, \mathrm{~T}=-10^{\circ} \mathrm{C}$ ).

dislocation density depend on the local strain, it might be expected that the dependence of the dislocation density on strain would have the same analytical form as that for the strain dependence of the crack density. Furthermore, the addition or removal of a dislocation is an impulse change of 1 in the dislocation density, and therefore the statistical model for an impulse proportionate change should apply to the strain dependence of the dislocation density.

The lognormal distribution has been found to be a useful descriptor for relaxation spectra measured in the anelastic range of strain for metals and alloys. Dislocation generation and relaxation are assumed to control these times for some mechanical behaviour observed in these materials (Nowick and Berry, 1972). Gold (in press) shows most of the initial crack populations develop within the same range of strain for columnar-grain ice. Considering the association of dislocations with the formation of cracks and with relaxation times for metals and alloys, it would be of interest to investigate whether the evolution of the dislocation density during the initial straining of ice has a lognormal dependence on strain.

Cole and Durell (2001) present a model for the strain dependence of the dislocation density. The parameters required for the model are obtained by a combination of incremental constant-load creep tests and cyclical anelastic straining between increments. The dislocation density for each amount of total creep strain is estimated from the loss compliance determined from the area of the hysteresis loop.

Cole (2001) presented an example of the strain dependence of the dislocation density for a sea-ice specimen subjected to a creep stress of $0.5 \mathrm{MPa}$. It is based on several strain increments covering the range 0 to $6 \times 10^{-3}$. His observed strain dependence of the dislocation density, based on several values taken from his figure 14, is shown for lognormal coordinates in Figure 9. The density is given as \% of an apparent maximum value of $N_{0}=1.3 \times 10^{9} \mathrm{~m}^{-2}$. This is

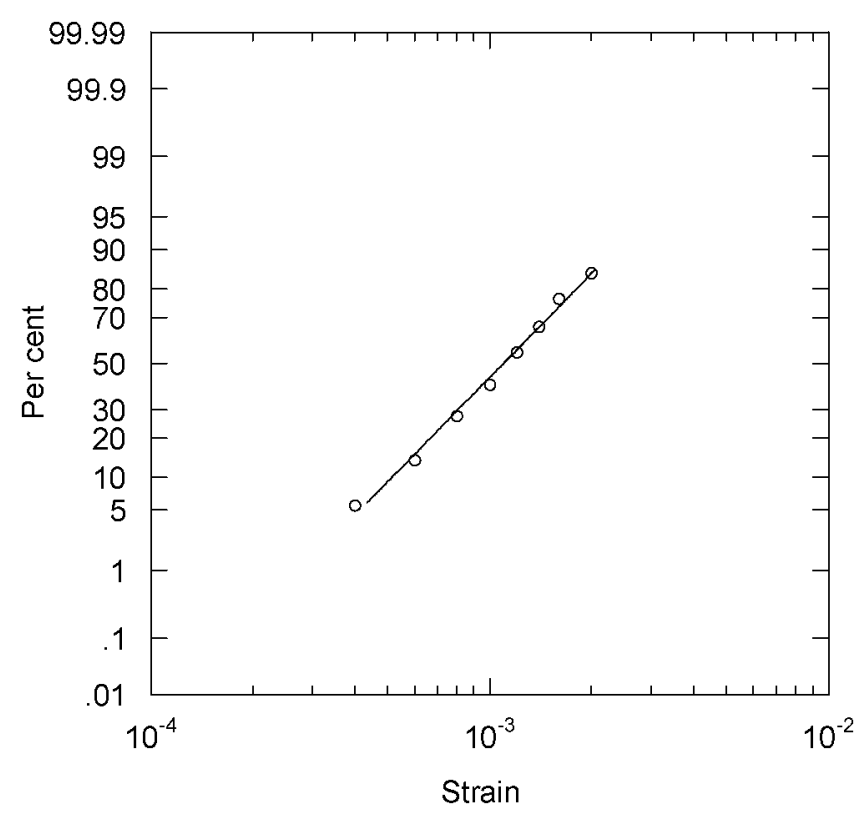

Fig. 9. Lognormal plot of the strain dependence of the dislocation density distribution ( $\%$ of estimated maximum value). The strain dependence of the dislocation density was obtained from Cole (2001): sea ice; constant stress $=0.5 \mathrm{MPa}$, strain $=$ $5.5 \times 10^{-3}, \mathrm{~T}=-10^{\circ} \mathrm{C}$.

the value associated with the maximum correlation coefficient $(=0.9974)$ for a least-squares exponential fit of the per cent of the maximum density to the logarithm of the strain. It is very close to the value that would be estimated from figure 14 in Cole (2001). The standard deviation of 0.59 is comparable to the value of 0.62 found for the strain dependence of the crack density for a creep stress of $0.6 \mathrm{MPa}$. The logarithmic mean strain of $11 \times 10^{-4}$ is appreciably smaller than the value of $30.4 \times 10^{-4}$ found for the crack density, as would be expected. Although the evidence is scanty, it does indicate one possible analytically based statistical connection between a crack-causing deformation process at the microscale and its manifestation at the macro-scale.

\section{DISGUSSION}

This study has provided additional support for the hypothesis that, for the conditions of the experiments, the development of the crack populations that precede failure in columnargrain ice is a random process. Statistical models, based on the assumptions of independence, randomness and impulse proportionate change, show that the lognormal distribution function should be a good descriptor of the crack-length distribution and of the strain dependence of the crack density.

The derivation of the models does not depend on material type or whether the material is columnar-grain or granular. They could apply, therefore, to any process in a multigrain material that satisfies the conditions of independence, randomness and impulse proportionate change. This was demonstrated through the application of the model for the strain dependence of the crack density to the strain dependence of acoustic emission in both columnar-grain and granular fresh-water ice, and to the strain dependence of the dislocation density for sea ice. Furthermore, it was shown in Gold (1997) that the lognormal distribution function provided a satisfactory description for the distribution in crack 
lengths measured by Cole (1986) in granular fresh-water ice. The agreement between the observations and the models provides strong evidence that the processes responsible for the formation of the primary crack populations involve random, impulse proportionate change.

The fact that the lognormal distribution function gives a useful description of the crack-length distribution and the strain dependence of the crack density for about $90 \%$ of their respective ranges does not prove that these two distributions actually have that statistical form. What has been shown is that the standard variable $z_{i}=\left[\ln (\mathrm{cl})_{i}-\overline{\ln (\mathrm{cl})}\right] / s$, for the crack-length distribution, and $z_{i}=\left[\ln (\varepsilon)_{i}-\overline{\ln (\varepsilon)}\right] / s$, for the strain dependence of the crack density, can be assumed normal, or nearly so, for about $90 \%$ of their range. In fact, Gold (1972a, b) showed that the probability distribution for the strain dependence of the crack density could be described by: $P=\alpha P_{1}+(1-\alpha) P_{2}$ where $P_{1}=1-\exp (A \alpha), P_{2}=$ $1-\exp \left(B \varepsilon^{2}\right)$, and $\alpha, A$ and $B$ are empirically determined constants. These expressions were based on a distribution function shown by Weibull (1951) to give a satisfactory statistical description for strength and yield.

Although the analysis has shown that cracks that formed under the conditions of the tests were random events, it was observed for some specimens that the shear stress affected their spatial distribution (Gold, 1999b). This indicates the sensitivity of the development of the primary crack population to boundary conditions. It was also found that the ratio of the number of grain-boundary cracks to the number of transcrystalline cracks depended on grain-size, strain rate and temperature (Gold, 1997). This is consistent with the observed correlation between the grain-boundary and transcrystalline crack populations. If the cracks that formed are considered as one population, not discriminating between grain-boundary or transcrystalline, as was necessarily the case for the analysis of the strain dependence of the crack density, they appeared to be truly independent, random events. The analysis, however, indicates a degree of correlation between the grain-boundary and transgranular populations that depends on structure and test conditions.

An important benefit of having a valid statistical descriptor for deformation-induced events, such as cracks and acoustic emission, is that it can provide a consistent method for the determination of a mean and standard deviation that are representative of the population. These characteristics can be used to study the dependence of the population on variables such as strain, strain rate, stress, temperature and structure, as shown by Gold (1972b, 1977, 1999b, in press). As the primary crack population is a random sample of the microscale causative processes, the distribution of those processes should have the same statistical form. That is, the characteristics of the macro-scale distribution give some indication of the statistical characteristics of the corresponding microscale population. In addition, the deviation of the assumed distribution from the observed one may yield useful information. For example, the difference at the high end between the actual crack-length distribution and the lognormal approximation suggests that the skewness and excess of the actual distribution may contain information on the effects of structure on the induced behaviour. For the strain dependence of the crack density it may indicate a change in behaviour, such as the initiation of failure or yield. One of the difficulties in establishing the stress, strain, strain rate and temperature dependence of the statistical characteristics of the primary crack population for a given type of ice, however, is their potential variability. Part of this may be due to variability in the structure of the ice and, if so, indicates the care that must be taken in making the ice and ice specimens and in determining their defining structural properties.

Knowledge of the stress, strain, strain rate, grain-size and temperature dependence of the statistical characteristics of the primary crack population for a given type of ice would be very relevant for the development of mathematical models of the mechanical response of damaged ice to uniaxial and multiaxial loads. This could be of some interest for exploring the boundaries between yield without failure by fracture and fracture by the extension of existing cracks, as studied by Schulson (1996) for both uniaxial and multiaxial stress conditions; cataclastic fracture that can occur under uniaxial stress conditions (Weiss and others, 1999); and the multiaxial stress conditions associated with the indentation of an ice cover by a structure (Jordaan and Xiao, 1999).

A difficulty in linking the statistically describable crack populations to failure by fracture, however, is that fracture is a unique, situation-dependent instability. It is a random variable and requires several observations to establish its nature under given conditions and the criteria for its occurrence. As stated earlier, the development of the primary crack population is a precursor to that instability. Predicting failure by fracture involves the same challenge, in principle, as determining when, where and how the causative microscale processes will initiate the first crack in the primary population. Wu and Niu (1995) and Kim and Shyam Sunder (1997) give an appreciation of that challenge in their respective development of an analytical description of the processes linking the primary crack population to the final failure event. Gold (1999a) suggested a crack-density-based criterion for failure of columnar-grain ice subjected to a uniaxial compressive stress, from his observations on the strain dependence of the crack density and published information on the strength of ice. Sinha (1991) determined crack densities of the same order for a crack-enhanced rheological model for yield based on grain-boundary sliding. Once the primary crack population begins to experience instability, the development of the failure process becomes increasingly determined by the interaction between cracks and crack surfaces, as shown by Schulson (1996), Jordaan and Xiao (1999) and Weiss and others (1999). The deformation behaviour of the ice tends to that of a Coulomb solid and can be described by the equations of classical mechanics.

Exploring the dependence of the characteristics of crack populations on the stress distribution may not be too difficult. For example, Weiss and Schulson (1995) and Weiss and others (1996) give information on the nature of the crack populations formed under multiaxial compression. In particular, it was observed that a uniform population of small grainboundary cracks was induced in randomly oriented granular ice by a hydrostatic compressive stress of about $11.5 \mathrm{MPa}$ applied at a strain rate of $10^{-3} \mathrm{~s}^{-1}$. Gold (1997) found that practically all the cracks formed in columnar-grain ice by a uniaxial stress applied at strain rates $>10^{-3} \mathrm{~s}^{-1}$ were in the grain boundary with at least one edge at a triple point. In his case, the plane of the cracks tended to be parallel to the applied compressive stress, whereas for Weiss and others (1996) they were randomly oriented. In both cases it was concluded that the cracks were due to the elastic anisotropy of the ice crystal, as indicated by the strength of the stress singularity induced at grain-boundary triple points. Schulson and Gratz (1999) observed three distinct regimes of Coulomb-like 
behaviour determined by the relative values of the principal compressive stresses applied to cube-shaped columnar-grain ice specimens. These examples and others that have been published provide useful guidance for the development of a stress-, strain-, time-, temperature- and structure-dependent statistical descriptor of the primary crack population and its incorporation into a mathematical model of mechanical behaviour.

\section{GONGLUSIONS}

The study has demonstrated that, for the conditions of the experiments, the formation of cracks during the initial straining of columnar-grain ice by a compressive stress applied perpendicular to the long direction of the grains is a random process. Statistical models, based on independence, randomness and change proportional to the population value at the time of the change, confirm that the lognormal distribution function is a good descriptor for the crack-length distribution and for the strain dependence of the crack density. The models do not depend on material or whether it is columnar-grain or granular and so would apply to any process in a multigrain solid that satisfies the conditions of independence, randomness and impulse proportionate change. As each crack is a random sample of the causative microscale processes, the statistical characteristics of the crack distributions should mirror the statistical characteristics of the causative microscale populations. The random, primary crack population that forms during the initial straining serves as the precursor to fracture, the conditions for which are normally determined empirically within the framework of classical mechanics. The straindependent model appears to be consistent with the strain dependence of the acoustic emission for polycrystalline ice subject to compressive stress, and may be consistent with the strain dependence of the dislocation density.

\section{AGKNOWLEDGEMENTS}

The author is deeply grateful for the opportunity provided by the Institute for Marine Dynamics of the National Research Council of Canada to carry out the study of crack formation under constant-strain-rate conditions. He appreciates, in particular, the support and interest of S. J. Jones in this work and the most valuable assistance of T. Slade in preparing specimens and conducting the experiments. J.W. Glen handled the paper as Scientific Editor.

\section{REFERENGES}

Aitchison, J. and J. A. C. Brown. 1969. The lognormal distribution. Cambridge, Cambridge University Press.

Cole, D. M. 1986. Effect of grain size on the internal fracturing of polycrystalline ice. CRREL Rep. 86-5.

Cole, D. M. 2001. The microstructure of ice and its influence on mechanical properties. Eng. Frac. Mech., 68(17-18), 1797-1822.

Cole, D. M. and G. D. Durell. 2001. A dislocation-based analysis of strain history effects in ice. Philos. Mag. A, 81 (7), 1849-1872.

Cramér, H. 1966. Mathematical methods of statistics. Princeton, NJ, Princeton University Press.
Frost, H. J. and V. Gupta. 1993. Crack nucleation mechanisms and fracture toughness measurements in freshwater ice. In Ice mechanics. Vol. AMD-163. New York, American Society of Mechanical Engineers. Applied Mechanics Division, 235-250

Glen, J.W. and M. F. Perutz. 1954. The growth and deformation of ice crystals. f. Glaciol., 2(16), 397-403/395-396.

Gold, L.W. 1960. The cracking activity in ice during creep. Can. 7. Phys, 38(9), 1137-1148.

Gold, L. W. 1963. Deformation mechanisms in ice. In Kingery, W. D., ed. Ice and snow: properties, processes, and applications. Cambridge, MA, M.I.T. Press, 8-27.

Gold, L.W. 1972a. The failure process in columnar-grained ice. (Ph.D. thesis, McGill University, Montréal, Que.)

Gold, L.W. 1972b. The process of failure of columnar-grained ice. Philos. Mag., 26(2), 311-328.

Gold, L.W. 1977. Engineering properties of fresh-water ice. F. Glaciol., 19(81), 197-212.

Gold, L.W. 1997. Statistical characteristics for the type and length of deformation-induced cracks in columnar-grain ice. F. Glaciol., 43(144), 311-320.

Gold, L.W. 1999a. A statistical basis for the streng th of columnar-g rain ice. In Shen, H.T., ed. Ice in surface waters. Vol. 1. Rotterdam, A. A. Balkema, 529-535.

Gold, L.W. 1999b. Statistical characteristics for the strain-dependent density and the spatial position for deformation-induced cracks in columnargrain ice. f. Glaciol., 45(150), 264-272.

Gold, L.W. In press. Strain and temperature dependence of crack populations in columnar-grain ice. Can. 7. Phys.

Jordaan, I. J. and J. Xiao. 1999. Compressive failure of ice. In Shen, H.T., ed. Ice in surface waters. Vol. 2. Rotterdam, A. A. Balkema, 1025-1031.

Kim, J. and S. Shyam Sunder. 1997. Statistical effects on the evolution of compliance and compressive fracture stress of ice. Cold Reg. Sci. Technol., 26(2), 137-152.

Nowick, A. and B. Berry. 1972. Anelastic relaxation in crystalline solids. New York, Academic Press.

Petrenko, V. F. and R.W.Whitworth. 1999. Physics of ice. Oxford, etc., Oxford University Press.

St. Lawrence, W. F. and D. M. Cole. 1982. Acoustic emissions from polycrystalline ice. Cold Reg. Sci. Technol., 5(3), 183-199.

Sanderson, T. J. O. 1988. Ice mechanics: risks to offshore structures. London, etc., Graham and Trotman

Schulson, E. M. 1996. The failure of ice under compression. In Arsenault, R. J. and 6 others, eds. The Johannes Weertman Symposium. Warrendale, PA, Minerals, Metals and Materials Society, 363-374.

Schulson, E. M. and E.T. Gratz. 1999. The brittle compressive failure of orthotropic ice under triaxial loading. Acta Mater., 47(3), 745-755.

Sinha, N. K. 1989. Elasticity of natural types of polycrystalline ice. Cold Reg. Sci. Technol., 17 (2), 127-135.

Sinha, N. K. 1991. Kinetics of microcracking and dilatation in polycrystalline ice. In Jones, S. J., R. F. McKenna, J. Tillotson and I. J. Jordaan, eds. Ice-structure Interaction. IUTAM-IAHR Symposium, St. Fohn's, Nerefoundland, Canada. Berlin, etc., Springer-Verlag, 69-87.

Tvergaard, V. and J.W. Hutchinson. 1988. Microcracking in ceramics induced by thermal expansion and elastic anisotropy. 7. Am. Ceramic Soc., 71(3), 157-166.

Weertman, J. 1973. Creep of ice. In Whalley, E., S. J. Jones and L. Gold, eds. Physics and chemistry of ice. Ottawa, Ont., Royal Society of Canada, 320-337.

Weibull, W. 1951. A statistical distribution function of wide applicability. $\mathcal{F}$. Appl. Mech., 18, 293-297.

Weiss, J. and E. M. Schulson. 1995. The failure of fresh-water granular ice under multiaxial compressive loading. Acta Metall. Mater., 43(6), 2303-2315.

Weiss, J., E. M. Schulson and H. J. Frost. 1996. The nucleation of microcracks in ice cubes compressed equally on all boundaries. Philos. Mag. A, 73(5), 1385-1400.

Weiss, J., N. Hotellier and M. Gay. 1999. The coupling between viscoplastic deformation and damage in ice. In Shen, H. T., ed. Ice in surface waters. Vol. 2. Rotterdam, A. A. Balkema, 967-972.

Wu, M. S. and J. Niu. 1995. Mechanical predictions of the compressive failure of ice: model development. Mech. Mater., 20(1), 9-32.

Xiao, J. and I. J. Jordaan. 1996. Application of damage mechanics to ice failure in compression. Cold Reg. Sci. Technol., 24(3), 305-322 